Revista Destaques Acadêmicos, Lajeado, v. 11, n. 1, 2019. ISSN 2176-3070

DOI: http://dx.doi.org/10.22410/issn.2176-3070.v11i1a2019.2161

http://www.univates.br/revistas

\title{
ANÁLISE DO MERCADO DE TRABALHO A PARTIR DA PERCEPÇÃO DE PESSOAS DESEMPREGADAS
}

\author{
Sonimara Debortoli ${ }^{1}$, Liciane Diehl ${ }^{2}$, Gabriel Machado Braido ${ }^{3}$
}

Resumo: Conquistar uma vaga de emprego tem sido um grande desafio nos últimos tempos devido à crise econômica que o Brasil está passando. Assim, este estudo propõe analisar a percepção de pessoas desempregadas em relação à atual situação do mercado de trabalho. Busca também compreender os reais motivos do aumento significativo da taxa de desemprego e apontar os impasses entre oferta e procura de emprego. Para tanto, foram aplicados questionários com questões fechadas e uma aberta a sujeitos desempregados do Vale do Taquari/RS, caracterizando essa pesquisa como quantitativa e qualitativa. Os resultados demonstraram que o desemprego afeta pessoas sem distinção de gênero, idade e grau de escolaridade, e que, mesmo estando desempregadas, as pessoas estão otimistas em relação às perspectivas de conseguir um trabalho, permanecem constantemente na busca por uma vaga e por qualificação. Para se manterem financeiramente, buscam alternativas de renda em atividades informais e contam com a ajuda de pessoas próximas. Ainda, destacam que as exigências por parte das empresas no momento da seleção estão cada vez mais rigorosas, demandam pessoas com experiência e qualificações específicas, banindo muitas de conseguir uma oportunidade. Este estudo mostrou-se importante na medida em que ampliou o conhecimento referente à atual situação do mercado de trabalho e a situação do desemprego que afeta uma grande diversidade de pessoas e aumenta cada vez mais a concorrência por uma vaga, sendo assim imprescindível conhecimento e qualificação para estar à frente do mercado.

Palavras-chave: Desemprego. Emprego. Mercado de trabalho.

1 Bacharel em Administração pela Universidade do Vale do Taquari - Univates. sdebortoli@universo.univates.br

2 Doutoranda em Psicologia (Unisinos) e professora assistente da Universidade do Vale do Taquari - Univates. lici@univates.br

3 Doutorando em Administração (Unisinos) e professor assistente da Universidade do Vale do Taquari - Univates. gabrielb@univates.br 


\section{INTRODUÇÃO}

Com a atual crise econômica que o Brasil vem passando, as notícias que circundam em jornais, televisão, redes sociais, entre outros meios de comunicação, mostram diariamente que são várias as consequências ocasionadas pela recessão. Uma reportagem da Folha de São Paulo de 17 de maio de 2018 mostra que a taxa de subutilização da força de trabalho, a qual inclui pessoas desempregadas, que gostariam de trabalhar e aqueles que desistiram de buscar por uma vaga de emprego, bateu recorde no primeiro trimestre deste ano (24,7\%). Isso representa 27,7 milhões de pessoas nestas condições, o maior número desde que a série história teve início em 2012.

Segundo a Pesquisa Nacional por Amostra de Domicílios Contínua (PNAD Contínua), divulgada pelo Instituto Brasileiro de Geografia e Estatística (IBGE) em 27 de abril de 2018, a taxa de pessoas desocupadas no trimestre encerrado em março de 2018 foi estimada em 13,1\%, sendo 1,3 ponto percentual acima da taxa do trimestre encerrado em dezembro de $2017(11,8 \%)$ e teve queda de 0,6 ponto percentual comparado ao trimestre de janeiro a março de $2017(13,7 \%)$. Isso representa 13,7 milhões de pessoas desocupadas e 11,2\% a mais (cerca de 1,4 milhões de pessoas) que o contingente observado entre outubro e dezembro de 2017. Se comparado ao igual trimestre do ano passado, onde havia 14,2 milhões de desocupados, esta estimativa teve queda de 3,4\%. Referente ao número de empregados com carteira assinada (32,9 milhões), este apresentou redução de 1,5\% comparado ao igual trimestre de 2017, ou seja, cerca de 493 mil pessoas a menos nesta condição.

Conforme mencionado por Barbieri (2014), no tempo atual não mais os ativos físicos de uma organização são os responsáveis por manter a sobrevivência da empresa, mas sim, o conhecimento é que se tornou primordial para geração de valor e riquezas às organizações e este somente é obtido através das pessoas. Diferentemente da sociedade industrial, agora os fatores de grande importância são o talento, a inteligência e o próprio conhecimento aplicados à solução dos problemas das empresas.

Segundo Gil (2001), há uma inquietude com relação ao futuro das instituições políticas e econômicas. O que se pode, no entanto, afirmar com convicção é que a ciência da Administração vem tendo cada vez mais desafios no intuito de superar um número crescente de problemas resultantes da transformação que o mundo está passando. Essa transformação é caracterizada pela redução da economia de base industrial e o surgimento de uma nova ordem econômica definida por um novo recurso básico: o conhecimento. O autor complementa que, com isso, a Gestão de Pessoas é o ramo da Administração que está sendo mais desafiado, principalmente porque sua matéria-prima é justamente o conhecimento. Portanto, se as empresas quiserem progredir, ou pelo menos sobreviver, terão de ajustar-se rapidamente a esse ritmo de mudança. E para isso, necessitarão de trabalhadores cada vez mais 
qualificados, os quais devem ter uma capacidade de aprendizagem continua para serem competitivos.

Lacombe (2011) relata que o downsizing (enxugamento, reestruturação da empresa) pode tornar as empresas mais competitivas. As demissões de pessoas quando realizadas bem planejadas e bem comunicadas, geram redução de custos e otimização de processos para as organizações, fatores estes considerados essenciais pela competição global. Por outro lado, tal fato afeta diretamente a empregabilidade, gerando um cenário hesitante para os trabalhadores.

Desta forma, o objetivo geral desta pesquisa é identificar qual a atual situação do mercado de trabalho do Vale do Taquari-RS na percepção de desempregados. Os objetivos específicos desta pesquisa são: (i) traçar o perfil das pessoas em atual situação de desemprego; (ii) analisar a razão pela qual muitas pessoas estão em situação de desemprego na percepção de pessoas desempregadas; (iii) verificar os recursos que estão sendo tomados pelo públicoalvo diante dessa situação; (iv) apontar os impasses entre oferta e procura de emprego na percepção de pessoas desempregadas. Assim, a pesquisa seguiu a abordagem quantitativa e qualitativa, sendo utilizados questionários com questões fechadas e uma questão aberta para a coleta de dados. Foram convidados a participar, desse estudo, sujeitos desempregados há, no mínimo, seis meses.

Este estudo justifica-se pela importância de ampliar o conhecimento referente à atual situação do mercado de trabalho e o desemprego. Acredita-se que os resultados deste estudo auxiliem estudantes, executivos, trabalhadores e público em geral na compreensão das condições atuais do mercado de trabalho e do desemprego.

\section{REFERENCIAL TEÓRICO}

\subsection{Mercado de trabalho}

Para Carvalho (2008), o mercado de trabalho diz respeito às ofertas de trabalho ou emprego oferecidas pelas organizações, em determinada época ou lugar, e sofre instabilidade decorrente do número de empresas existentes em certa região e sua demanda, o que gera disponibilidade de vagas e, portanto, oportunidades de emprego. No mesmo sentido, Banov (2012) entende que o mercado de trabalho nada mais é do que as vagas de emprego oferecidas pelas empresas e a oferta e procura das mesmas que está refletido nos critérios de seleção de pessoal dentro do sistema de recursos humanos das empresas.

Carvalho (2008, p. 58) complementa que os termos de oferta e procura estão ainda relacionados com os segmentos do mercado, como por exemplo, "por setores de atividades (empresas metalúrgicas, automobilísticas, do ramo bancário etc.), por tamanho (micro, pequenas, médias e grandes empresas), 
por origem (estatais, mistas, privadas nacionais e multinacionais) ou ainda, por localidades (São Paulo, Belo Horizonte, Rio de Janeiro etc.)". Diante disso, pode-se dizer que o mercado de trabalho passa por três situações: oferta maior do que a procura, oferta menor do que a procura e oferta igual à procura.

Segundo Chiavenato (2009), quando há oferta maior do que a procura, há excesso de ofertas de emprego pelas empresas e escassez de candidatos. Nesse caso, as organizações acabam investindo mais em recrutamento, os critérios de seleção se tornam mais flexíveis, investem mais em treinamento para compensar a inadequação dos candidatos, os salários são mais altos para atrair mais candidatos, sem mencionar na concorrência entre as empresas na disputa pelos mesmos candidatos. Já para os candidatos, esta situação representa mais oportunidades de trabalho, podem escolher onde trabalhar, passam a fazer reivindicações de aumento de salário na empresa em que atuam e se não estiverem satisfeitos, é o momento de procurar um novo emprego.

O autor acrescenta que, na situação em que a oferta é menor do que a procura, ocorre o inverso da situação anterior. Há excesso de candidatos e escassez de ofertas de emprego, as organizações fazem baixos investimentos em recrutamento e treinamento, a seleção de pessoas é mais rigorosa, os salários também tendem a ser menores e a competitividade entre as empresas é inexistente. Porém, para os candidatos, a concorrência aumenta devido à disputa por uma mesma vaga de emprego, chegam a candidatar-se para cargos inferiores às suas qualificações profissionais e aceitando salários menores. De acordo com Banov (2012), o ponto de equilíbrio da situação de mercado se dá quando a oferta é equivalente à procura de emprego.

Para os candidatos que querem fugir da concorrência entre si por uma boa vaga de emprego, é importante a busca constante de qualificação. De acordo com Araújo, Albuquerque e Silva (2009), a chegada de novas e sofisticadas tecnologias causou grande impacto no mercado de trabalho e na economia em geral. À proporção que vai se ampliando ao uso de tecnologias dentro de uma organização, ocorre o aumento do nível de complexidade das atividades, o que acarreta maior autonomia e responsabilidade por parte do trabalhador, sendo assim exigido um grau maior de competência e qualificação.

Lena (2010) afirma que, no mundo em que se vive, há grandes divergências sociais, ainda mais intensas devido ao processo de globalização. No entanto, a igualdade ao acesso às bases de informação e conhecimento têm sido possível para a maioria da população. Os autores complementam que, ainda assim, o trabalhador contemporâneo tem o desafio de filtrar e transformar todo esse conhecimento e informação em competências para que possam ser usadas para gerar empregabilidade.

Nesse sentido, Lena (2010, p. 35) refere que a, "empregabilidade é a capacidade do indivíduo de conseguir novas oportunidades de emprego, manter-se empregado e também de conseguir promoções, por meio de seus conhecimentos, habilidade e atitudes." Empregabilidade sempre existiu, porém 
estava presente nos altos escalões corporativos onde era mais cobrado devido à necessidade de gerar resultados positivos ser mais perceptível. Esta, ainda, é instável como o desenvolvimento do profissional.

Marras (2010) coloca que, mediante esse conceito, os trabalhadores obrigaram-se a compreender que o compromisso de sua formação/ especialização é tão somente de cada um, e não mais da empresa onde estão ou irão trabalhar. Com base nesse raciocínio, cada indivíduo que deseja entrar no mercado de trabalho deverá pensar que, para ser incluído, terá de, obrigatoriamente, ser melhor que os demais que estejam requerendo um trabalho formal.

Almeida (2009) complementa que as relações de trabalho entre a organização e empregado também passaram por muitas mudanças. A ideia de um profissional que passava a maior parte da sua vida em uma única empresa deixou de ser a realidade. Nota-se que uma grande parcela de profissionais muda de organização com maior freqüência. Assim, as empresas também adotam o emprego de mais trabalhadores temporários.

O termo trabalho é preferido ao de emprego, pois este inclui os profissionais autônomos que proporcionam seus serviços diretamente ao mercado e ainda podem ser contratados pelas empresas como prestadores de serviços ou consultores. Essa disparidade das modalidades de contratação que atualmente as empresas necessitam gerenciar exige uma maior flexibilidade da legislação trabalhista, a que muitos criticam por ter levado a uma precarização do trabalho (ALMEIDA, 2009).

O autor acrescenta que a terceirização de atividades para outras empresas, com o propósito de atentar para as atividades estratégicas da organização, auxilia para que a captação e seleção não ficassem limitadas à busca de profissionais no mercado, mas também a empresas parceiras, conduzindo a se reconsiderar os critérios normalmente utilizados para selecioná-las.

Lacombe (2011) complementa que a terceirização é apenas uma das formas de trabalho cuja disposição deve se acentuar no futuro próximo. $\mathrm{O}$ emprego com vínculo empregatício e a composição vertical das atividades tem tendência a diminuir. $\mathrm{O}$ trabalho será cada vez mais realizado por empresas terceirizadas, por profissionais autônomos que atuam dentro da empresa ou até mesmo, em sua própria residência, entre tantas outras alternativas.

Desta forma, torna-se essencial entender o conceito de recrutamento, para que esteja claro e perceptível como se dá esse processo entre o candidato e a organização. Para Ivancevich (2008), o processo de recrutamento se inicia na tentativa de localizar trabalhadores com as habilidades e as atitudes que são pretendidas pela organização e os mais adequados para as tarefas a serem executadas. 


\subsection{Recrutamento}

Para que as empresas encontrem o trabalhador com o perfil e qualificações adequados para uma vaga na organização, é necessário, primeiramente, que sejam divulgadas as vagas em aberto e feito um recrutamento dos trabalhadores que se candidataram para a vaga. Ivancevich (2008) menciona que o recrutamento relaciona-se com as atividades da organização, as quais determinam a quantidade e o perfil de candidato que se apresenta para uma vaga e a aceitação ou não do emprego oferecido. Desta forma, o processo de recrutamento tem relação direta com a seleção e o planejamento de recursos humanos, sem mencionar que esta etapa consiste no primeiro contato entre as organizações e os futuros funcionários da empresa.

No ponto de vista de Chiavenato (2010), o recrutamento pode ser caracterizado como uma soma de técnicas e procedimentos os quais objetivam atrair candidatos potencialmente qualificados e habilitados para ocupar cargos dentro da organização. Basicamente se trata de um sistema de informação através do qual a organização divulga e oferece as oportunidades de emprego ao mercado de trabalho.

Ainda, Milkovich e Boudreau (2013, p. 162) afirmam que o "recrutamento é o processo de identificação e atração de um grupo de candidatos, entre os quais serão escolhidos alguns para posteriormente serem contratados para o emprego". Este processo não é importante apenas para a organização, se trata de um sistema de comunicação bilateral. Os candidatos querem saber informações relevantes sobre como será trabalhar nessa empresa e a empresa quer saber informações de que tipo de empregado será o candidato caso venha a ser contratado.

De acordo com Vizioli (2010), o recrutamento é o processo que primeiro visa identificar fontes de funcionários (talentos) para a empresa e, no momento certo, mobilizar estas fontes com a finalidade de encaminhar os candidatos mais adequados à etapa seguinte (seleção). O recrutamento é de extrema importância, pois quando conduzido de forma eficiente, economiza tempo e dinheiro durante o processo seletivo.

Ivancevich (2008) aborda diversos aspectos que afetam o processo de recrutamento do ponto de vista da organização e também do candidato. Em relação ao ponto de vista da empresa, interferem o conjunto de exigências para o recrutamento (especificação e descrição do cargo); as políticas e os procedimentos organizacionais (recrutamento externo e interno, contratação de pessoas deficientes, menor aprendiz, etc); e a imagem da organização (como a empresa é vista pelo público).

No ponto de vista do candidato, Ivancevich (2008) refere que esse possui habilidades, atitudes e preferências as quais são baseadas em experiência prévia profissional e influências de pessoas próximas. Isso afeta o recrutado de duas maneiras: como ele estabelece suas preferências de emprego (barreiras 
enfrentadas para encontrar seu emprego ideal) e como procura um emprego (modo como busca um emprego, auto-avaliação).

De acordo com Junior et al. (2014), é fundamental que o candidato ofereça algumas das exigências já fixadas pelo mercado de trabalho, por exemplo, estar atualizado, evidenciar capacidade de adaptação em um ambiente de mudanças rápidas, ter aptidão para trabalhar em equipe e trabalhar sob pressão. Estas são algumas características que colaboram de forma positiva para que os candidatos consigam superar suas dificuldades e apresentarem-se confiantes no momento dos testes.

Vale ressaltar que nos dias atuais os objetivos do recrutamento são bem amplos. Devido às mudanças constantes e a rapidez com que elas ocorrem, não basta atingir os objetivos, é necessário ultrapassá-los, pois poderão se tornar desatualizados em um curto espaço de tempo. Assim, o grande desafio é descobrir não apenas o melhor candidato, mas aquele que tem maior potencial (CARVALHO, 2008).

\subsection{O novo perfil do trabalhador}

Após a Revolução Industrial, o trabalho no campo foi substituído pelo trabalho nas fábricas. Com a Revolução da Informação e do Conhecimento, a mão de obra braçal foi trocada pela tecnologia e a maioria dos trabalhadores que deixou as fábricas começou a ingressar no comércio e na prestação de serviços (CARVALHO, 2008).

Conforme Almeida (2009), o mercado de trabalho passou por mudanças significativas, estas relacionadas com as políticas econômicas e sociais impostas pelos governos. O mercado atual tem como principais características o fim do emprego em massa, a eliminação de postos de trabalho, redução do mercado formal e crescimento do mercado informal, a escassez do trabalho e o desemprego estrutural.

O autor complementa que, devido ao avanço tecnológico, o mercado de trabalho passou a ser mais seletivo e novas profissões e perfis apareceram. Os requisitos para contratação ficaram mais rigorosos, principalmente em se tratando de formação e experiência, sem contar as competências comportamentais que também são muito relevantes.

Segundo Carvalho (2008), o chão de fábrica na atualidade não comporta mais trabalhadores com pouca ou nenhuma escolaridade. Sobrevivem somente aqueles que buscam se atualizar constantemente, pois as mudanças na tecnologia dentro da empresa ocorrem rapidamente, sempre há novos recursos, novos métodos. Também ocorrem mudanças nas relações de trabalho, como por exemplo, o trabalho a distância que já é realidade para muitos profissionais.

Nesse sentido, Dutra-Thomé e Koller (2014) complementa que o atual mercado de trabalho demanda maior investimento em educação e treinamento profissional, buscando sempre mais profissionais altamente qualificados. 
A variável "conhecimento" sempre foi um condutor importante em todos os momentos históricos do mundo do trabalho. Tanto as organizações quanto os empregados sempre souberam reconhecer que reter conhecimento representava uma parcela significativa de poder e uma força incomparável na produção de riqueza (MARRAS, 2010).

Segundo Lacombe (2011), a educação surge como prioridade evidente. A sociedade da informação e do conhecimento exige pessoas que estejam sempre em busca de aprendizado. Através da educação, pode-se aumentar a capacidade de avanços tecnológicos e fazer com que a democracia se torne mais operacional, os mercados menos desiguais e a distribuição de renda mais justa.

Dutra (2011) menciona que a visão de carreira (acordo dinâmico das expectativas entre a pessoa e a empresa) é bem diferente nas empresas onde, diante da crescente complexidade técnica e organizacional, as estruturas e estratégias que prevalecem são as que oferecem maior flexibilidade e agilidade para adaptação aos estímulos ambientais. Nestas empresas, é indispensável que os trabalhadores estejam em um contínuo processo de qualificação e com maior flexibilidade profissional. Assim, a responsabilidade pela administração de carreira é visualizada como sendo dividida entre a empresa e a pessoa.

O mesmo autor complementa que esta questão é resultado de mudanças nos padrões de relações de trabalho que vem sendo praticada pelas empresas submetidas a pressões concorrenciais mais acirradas. Para que estas empresas tenham vantagem competitiva na sua inserção no mercado, necessitam do engajamento e comprometimento das pessoas com os resultados de seu trabalho, os quais não podem ser impostos ao trabalhador, mas sim, resultados da motivação do mesmo em executar seu trabalho, de seus valores e de seus talentos e habilidades.

\section{PROCEDIMENTOS METODOLÓGICOS}

A pesquisa desenvolvida é caracterizada como exploratória e descritiva. De acordo com Gil (2012), a pesquisa exploratória tem como principal objetivo desenvolver, esclarecer e modificar conceitos e idéias, visando à elaboração de problemas mais precisos ou hipóteses que podem ser pesquisadas em estudos posteriores. Quanto à pesquisa descritiva, segundo o mesmo autor, esta tem como finalidade principal a descrição das características de certa população ou fenômeno ou estabelecimento de relações entre variáveis.

Quanto aos procedimentos técnicos, trata-se de uma pesquisa de campo. Vergara (2010) relata que a pesquisa de campo é a apuração prática realizada no local onde acontece ou aconteceu um fenômeno ou que possui elementos para explicá-lo. Lakatos e Marconi (2010) mencionam que a pesquisa de campo é utilizada com a finalidade de adquirir informações e/ou conhecimentos em relação a um problema, para o qual se procura uma resposta. 
Em relação à natureza de abordagem, trata-se de uma pesquisa quantitativa e qualitativa. Malhotra (2012) refere que a pesquisa quantitativa é o método de pesquisa que busca quantificar os dados e, geralmente, aplica alguma forma de análise estatística. Sampieri, Collado e Lucio (2013, p. 30) complementam que a pesquisa com enfoque quantitativo é fundamentado na medição numérica e no estudo estatístico para determinar padrões e comprovar teorias. Em relação à abordagem qualitativa, esta relaciona-se à interpretação da questão aberta nos questionários e, segundo Malhotra (2012), a variável qualitativa se refere a um método de pesquisa não estruturada e exploratória que proporciona compreensão do contexto de um problema.

A coleta de dados se deu na forma de questionário, que Lakatos e Marconi (2010, p. 184) definem como "um instrumento de coleta de dados, constituído por uma série ordenada de perguntas, que devem ser respondidas por escrito e sem a presença do entrevistador." O questionário foi especialmente criado para este estudo e foi composto por 19 questões fechadas (seis para definir o perfil dos respondentes - Bloco A - e 13, para levantar as informações que atendessem ao objetivo geral desse trabalho - Bloco B) e uma questão aberta. Segundo Fachin (2003), as questões fechadas são aquelas em que a pessoa escolhe sua resposta em um grupo de categorias criadas juntamente com a questão e as questões abertas são aquelas em que o pesquisado tem a condição de expor espontaneamente sobre o assunto que está sendo questionado. Em relação às questões fechadas, houve questões com duas opções de resposta (dicotômicas) ou a inclusão de várias opções (politômicas) (SAMPIERI; COLLADO; LUCIO, 2013).

Quanto à população-alvo, Vergara (2010) menciona que esta é o conjunto de elementos que possuem as características as quais serão objeto do estudo. Fizeram parte, desse estudo, pessoas em situação de desemprego residentes no Vale do Taquari-RS. O critério de inclusão foi estar desempregado há, no mínimo 6 meses. Nesse sentido, a amostra configurou o número de 40 respondentes.

Os dados foram coletados por meio de questionário eletrônico, o qual foi divulgado nas redes sociais (Facebook, Whatsapp, E-mail), possibilitando abranger o máximo de desempregados possível. Foi escolhida a divulgação pelas redes sociais, pois nessas foi observada expressiva concentração de divulgações de vagas de emprego, sendo assim, um atrativo para as pessoas que estão em situação de desemprego e que buscam uma oportunidade no mercado de trabalho.

Após a coleta dos dados quantitativos, foi feita a elaboração e classificação dos mesmos de forma sistemática, que passou pela seleção (exame minucioso dos dados, identificação de erros ou falhas); codificação (os dados são transformados em símbolos podendo ser tabelados e contados) e a tabulação (disposição dos dados em tabelas) (LAKATOS; MARCONI, 2010). Os dados quantitativos foram analisados e interpretados utilizando-se ferramentas 
estatísticas, planilha de Excel e a elaboração de gráficos. Dessa forma, os dados deste estudo foram avaliados por meio da estatística descritiva simples, a qual compreende a manipulação dos dados para resumi-los ou descrevê-los, buscando não inferir qualquer coisa que exceda os próprios dados (FREUND, SIMON, 2000).

Em relação aos dados qualitativos relativos à questão aberta, realizouse a análise de conteúdo. Caregnato e Mutti (2006) referem que a análise de conteúdo pode pertencer a um estudo tanto de abordagem qualitativa, quanto quantitativa. Explicam os autores que a análise de conteúdo é uma técnica de pesquisa que utiliza bastante a palavra, dessa forma, permite produzir deduções de forma prática e objetiva, ou seja, através dessa técnica, o analista categoriza as unidades de texto (palavras ou frases) repetidas, selecionando uma expressão que as representem.

\section{ANÁLISE E DISCUSSÃO DOS RESULTADOS}

Do total de 40 respondentes, $72,5 \%$ é do sexo feminino e $27,5 \%$ é do sexo masculino. A idade média dos respondentes fica em 30 anos, sendo que há uma variação entre 17 e 54 anos, o que demonstra que o desemprego afeta pessoas de diversas idades, não sendo exclusivo de pessoas em início de carreira profissional e sem experiência laboral ou de indivíduos mais velhos e ultrapassados em seus conhecimentos. Esse público (pessoas muito jovens ou pessoas mais velhas) geralmente é o mais atingido por preconceitos, por parte das empresas, em processos de recrutamento e seleção (JUNIOR et al., 2014). Um relato expressado na questão aberta desse estudo por uma respondente com 54 anos, Ensino Médio incompleto, separada/divorciada, desempregada há 7 meses vem ao encontro dessa análise: "Acredito que estou velha para o mercado de trabalho, não me sinto velha, mas há discriminação na idade".

Ainda, outra respondente com 28 anos, Ensino Médio completo, casada, desempregada há mais de um ano, diz que "Estão com muitas exigências, preferem mulheres sem filhos e pessoas que não estão com o nome no SPC."

Segundo Dessler (2014), a Constituição Federal deixa evidente a proibição de práticas discriminatórias quanto à raça, religião, violação à intimidade e à vida privada (normalmente acontece nas entrevistas de emprego), gênero, origem (estrangeiros), cor, idade, estado civil, admissão de trabalhador com deficiência, homossexuais, entre outros. A consulta a serviços de proteção ao crédito também é considerada uma prática discriminatória, pois impede que alguém inscrito em cadastro de inadimplentes em razão do desemprego tenha a oportunidade de se recolocar.

Por outro lado, pessoas jovens que buscam uma oportunidade ou, até mesmo, seu primeiro emprego, também encontram dificuldades no mercado de trabalho. Um respondente de 17 anos, com Ensino Médio incompleto, solteiro, desempregado há 8 meses diz que há “... pouca oportunidade para jovens que ainda 
não tem experiência." Outra participante, com idade de 18 anos, Ensino Superior em andamento, solteira e que nunca trabalhou, tem a mesma opinião: "Está extremamente exigente para com as pessoas que procuram seus primeiros empregos." Nestes casos pode-se observar que as empresas dão preferência para pessoas que tenham experiência.

Ainda, cabe ressaltar a gestão da diversidade, ou seja, a variedade da força de trabalho. De acordo com Dessler (2014), as equipes de trabalho devem ser compostas de funcionários com diferentes etnias, cultura, gênero, idade, religião, nacionalidade e deficiência. Essa diversidade, entretanto, pode provocar barreiras comportamentais que acabam prejudicando os relacionamentos interpessoais, como por exemplo, os estereótipos. Dizer que pessoas mais velhas não têm capacidade de trabalhar duro ou então os jovens da Geração Y são instáveis no trabalho, são alguns exemplos.

Segundo Santos (2008), o desemprego causa sentimentos de vergonha, rejeição, abandono, insegurança, angústia e ansiedade que entram no cotidiano das pessoas e acabam caracterizando uma sociedade marcada pela indiferença, desconfiança e falta de compromisso mútuo entre as pessoas, as quais buscam soluções individuais para problemas ocasionados socialmente.

Quanto ao grau de escolaridade, 27,5\% dos respondentes possui Ensino Médio completo, seguido por Ensino Superior completo (25\%), Ensino Médio incompleto (17,5\%), Ensino Superior em andamento (17,5\%) e 12,5\% indicou que parou ou trancou os estudos do Ensino Superior. Portanto, percebe-se que a maior parte dos respondentes têm um grau de escolaridade em nível médio e superior. Embora os autores refiram que o "novo perfil dos trabalhadores" requer, nos dias atuais, maior qualificação (ALMEIDA, 2009; CARVALHO, 2008; DUTRA-THOMÉ; KOLLER, 2014; MARRAS, 2010; LACOMBE, 2011; DUTRA, 2011), a realidade do desemprego é também das pessoas que apostam na continuidade dos seus estudos.

Referente ao estado civil, $50 \%$, ou seja, a metade dos respondentes é solteiro, $22,5 \%$ é casado, $17,5 \%$ mantém união estável e $10 \%$ é separado/ divorciado. Ainda, 40\% afirma morar com outros familiares, $25 \%$ mora com companheiro(a) e a mesma porcentagem mora com companheiro(a) e filho(s). Também, a maioria (65\%) afirma não possuir dependentes e $35 \%$ possui dependentes. Nesse sentido, é possível inferir que o desemprego e, consequentemente, a falta de renda, não causa maiores reflexos na vida pessoal porque a maior parte das pessoas não possui outros dependentes, ou seja, não há outras pessoas que necessitam do seu ganho para sobreviver, fazendo com que a situação seja mais fácil de administrar.

Quanto ao tempo de desemprego, há uma variação entre 1 mês e 72 meses, ficando assim, uma média de 14 meses de tempo de desemprego. Ainda, 47,5\% afirma que está desempregado por motivo de demissão por parte da empresa, 27,5\% afirma ser por outros motivos (dificuldades de conciliar demandas pessoais com o trabalho, problema de saúde, nunca trabalhar, 
entre outros) e $25 \%$ pediu demissão. Percebe-se, assim, que é involuntário as pessoas estarem desempregadas. Segundo a Pesquisa Nacional por Amostra de Domicílios Contínua (PNAD Contínua) em matéria divulgada no Jornal do Comércio - Porto Alegre em 31 de agosto de 2016, o volume de rendimentos dos trabalhadores que continuam ocupados reduziu $4 \%$ no trimestre encerrado em julho, o que sustenta o círculo vicioso do desemprego. Ou seja, devido ter menos pessoas consumindo, o comércio terá menos saída, a indústria irá produzir menos e conseqüentemente, terão mais pessoas demitidas.

Quando questionados sobre o que têm feito para administrar os custos pessoais diante do desemprego, 52,5\% respondeu que fazem atividades alternativas sem carteira assinada, 42,5\% conta com ajuda de amigos e familiares e $17,5 \%$ assinalou "outros". O número de $52,5 \%$ e possivelmente os 17,5\% estejam nos índices revelados pela Pesquisa Nacional por Amostra de Domicílios Contínua (PNAD Contínua) divulgada pelo IBGE em 30 de setembro de 2016, que demonstrou que há 10,2 milhões de pessoas empregadas sem carteira assinada e 22,2 milhões de pessoas que trabalham por conta própria.

Um total de $97,5 \%$ dos respondentes afirmou estar procurando um novo emprego, o que demonstra aparentemente que a renda provinda do trabalho informal não é suficiente para prover o sustento. Na questão "Você está buscando um novo emprego na/em", era possível que o respondente assinalasse mais de uma alternativa. Desta forma, $60 \%$ está procurando uma oportunidade na área em que atuava anteriormente, 57,5\% busca uma vaga em qualquer área e $45 \%$ almeja um emprego na sua área de formação. Esse resultado demonstra que expressiva parte dos respondentes optou por buscar um trabalho na área em que já atuava, seguido de um número próximo de respostas relativas à busca de colocação profissional em qualquer área, indicando que as pessoas não estão dando preferência para uma vaga específica.

Na questão que investigou de que forma o respondente busca um novo emprego, também era possível assinalar mais de uma opção. Nesse caso, a opção mais utilizada $(87,5 \%)$ foi o envio do currículo por e-mail para diversas empresas supondo que isso se deve à comodidade e praticidade, podendo abranger um número maior de empresas e mais oportunidades. As outras opções foram a entrega de currículo pessoalmente em empresas conhecidas $(60 \%)$, redes sociais (páginas no Facebook) $(57,5 \%)$, agências de emprego $(52,5 \%)$, SINE $(42,5 \%)$ e preenchimento de ficha de cadastro diretamente na empresa $(42,5 \%)$.

Referente ao retorno positivo na busca por um novo emprego (ser chamado para uma entrevista, por exemplo), há um equilíbrio. Um conjunto de $55 \%$ participantes respondeu que obteve um retorno positivo e $45 \%$ não obteve retorno. Ainda, aqueles que responderam que obtiveram retorno positivo, avaliam a forma como a empresa conduz o processo de seleção de forma regular $(69,2 \%)$, seguido pelos conceitos péssimo $(23,1 \%)$, muito ruim $(3,8 \%)$ e muito bom (3,8\%). De acordo com Júnior et al. (2014), o recrutamento 
e seleção acabam se tornando uma dificuldade para as pessoas que buscam um emprego, "pois as empresas procuram pessoas com habilidades e atitudes muito específicas às necessidades que demanda a vaga." (p. 10).

Quando questionados sobre a dificuldade de conseguir um novo trabalho, 92,5\% respondeu que percebe dificuldade. A questão seguinte, que investigou a percepção dos respondentes sobre se as empresas têm aumentado o nível de exigência sobre a qualificação dos candidatos, demonstrou os mesmos índices, revelando que a maioria $(92,5 \%)$ acredita que as empresas estão buscando pessoas mais qualificadas.

Infere-se que essas questões são as que mais mobilizaram os participantes do estudo, uma vez que a questão aberta (opinião em relação ao mercado de trabalho) contemplou expressões de desabafo em relação à dificuldade de conseguir um novo trabalho e sobre a exigência de qualificação dos candidatos por parte das empresas. Muitos colocam que realmente está difícil conseguir um emprego e isso se deve a diversos fatores como, por exemplo, a crise econômica e política que nosso país está passando, a exigência de pessoas qualificadas e com experiência, a concorrência entre os candidatos, a preferência por pessoas mais jovens e, até mesmo, a prática de discriminação. O relato de uma respondente de 23 anos, com Ensino Superior completo, solteira e desempregada há 8 meses retrata essas reflexões:

Péssimo. Muitas empresas exigem experiências em áreas muito específicas, ou experiência de muitos anos [...]. Quanto às entrevistas de emprego, em 8 meses apenas fui chamada para duas, e ambas as empresas não foram nem capazes de me dar uma resposta, nem para dizer não. A situação no mercado está muito complicada, com muitas demissões e poucas contratações.

Da mesma forma, o comentário de uma respondente de 39 anos, com Ensino Médio completo, casada, desempregada há 9 meses, expressa insatisfação com a situação atual do mercado de trabalho:

[...] sou formada em curso téc adm [Técnico em Administração] e tenho outros cursos menores como em recursos humanos concluído à quatro anos porém nunca consegui atuar na área sempre pedem experiência. Mas como ter experiência se ninguém te da uma chance uma oportunidade? Acho que falta vontade das empresas em querer ensinar pessoas novas nestas áreas, e com certeza perdem pessoas com grandes talentos e com muita vontade de trabalhar.

De acordo com Mészáros (2002) citado por Santos (2008), o desemprego não está restrito somente à dificuldade dos trabalhadores não-qualificados, mas abrange também muitos trabalhadores "altamente qualificados", que juntos disputam os escassos empregos disponíveis. Nota-se que não é suficiente uma formação, mas experiência na área em que a vaga está sendo divulgada. 
Outra questão relacionada à qualificação profissional foi saber se os respondentes buscam constantemente atualizar/ampliar seu conhecimento. A maioria busca se aperfeiçoar $(80 \%)$, o que representa um desafio, pois uma pessoa desempregada, sem uma renda fixa mensal fica restrita a ter condições de custear qualquer projeto de atualização e ampliação do seu conhecimento. $\mathrm{O}$ relato de uma respondente de 47 anos, com Ensino Médio incompleto, em uma união estável, desempregada há 12 meses, é que "Está sobrando mão de obra, mas com pouca qualificação". Supõe-se que as empresas deveriam oportunizar às pessoas um trabalho permitindo ao mesmo tempo que elas se qualifiquem.

Um total de $80 \%$ dos respondentes diz que já pensou em mudar de área tendo em vista dificuldades em encontrar emprego na sua área de formação e $20 \%$ continuam buscando um emprego na área em está qualificado. Portanto, devido à dificuldade para conseguir uma vaga no mercado de trabalho, as pessoas procuram emprego em outras áreas e não somente na específica de sua formação.

Entretanto, apesar de todas as dificuldades e a situação de estarem desempregados, os respondentes mostraram-se mais otimistas do que pessimistas quanto às perspectivas de conseguir um trabalho $(45 \%$ está otimista, seguido de $37,5 \%$ pessimista e 17,5\% indiferente). A opinião de um respondente de 43 anos, com Ensino Superior completo, separado/divorciado, desempregado há 16 meses, é:

Em 26 anos de atuação profissional estou me deparando com um grau moderado de dificuldade, tranquilamente compreensível pela situação política e principalmente econômica. Acredito que estabilizamos os índices negativos e passamos a diminuir os mesmos. Tenho certeza de que, de forma lenta e gradual, iremos retomar o crescimento de forma tímida. Ainda específico em nossa região, o mercado de trabalho respira diferente, pois tem um oxigênio que é importante ressaltar, a área de alimentos e bebidas. A diversificação das indústrias alimentícias (carne, leite, bebidas balas) nos proporciona um restabelecimento antecipado ao mercado nacional.

É importante acreditar que, embora ainda não tenha sido possível o mercado de trabalho se recompor, é plausível que esse quadro de desemprego e precarização de fato se transformem em condições mais dignas de trabalho. Sem dúvida presencia-se alguns avanços no sentido da diminuição das desigualdades sociais; é provável que a sociedade esteja no caminho certo, mas ainda não conquistou-se a velocidade necessária (SANTOS, 2008).

\section{CONCLUSÃO}

Entender a atual situação do mercado de trabalho e o desemprego que afeta milhões de brasileiros é importante, pois é possível identificar onde se 
encontram as maiores barreiras e dificuldades que os trabalhadores se deparam no momento de conseguir um emprego. O desemprego coloca-se como um problema social que gera instabilidade e sentimento de insegurança abrangente em trabalhadores de todos os ramos e setores de atividade.

Este estudo propôs identificar qual a atual situação do mercado de trabalho do Vale do Taquari-RS a partir da percepção de desempregados e este objetivo foi alcançado por meio da pesquisa aplicada. $O$ primeiro objetivo específico propunha traçar o perfil das pessoas em atual situação de desemprego e, assim, identificou-se que o desemprego afeta pessoas de diferentes idades, qualificadas ou não, e que a experiência é um fator bastante considerado pelas empresas no momento do recrutamento e seleção de candidatos, além da exigência por qualificações específicas para as vagas de trabalho.

Apesar das dificuldades e a enorme concorrência por uma vaga de emprego, os desempregados não se sentem retraídos em procurar um novo trabalho, pois os resultados mostraram que, devido às empresas exigirem candidatos cada vez mais qualificados, eles estão indo em busca desta qualificação e ainda se sentem otimistas para conseguir uma oportunidade no mercado de trabalho. Conforme proposto no segundo objetivo específico, observou-se que a razão pela qual muitas pessoas estão desempregadas se deve às exigências em qualificação por parte das empresas e a instabilidade atual do mercado. É nítido que, com a evolução do mercado de trabalho, com as tecnologias cada vez mais presentes, um novo perfil de trabalhador se faz necessário, e este tem como principal característica o conhecimento contínuo.

Ainda, cabe ressaltar que a crise econômica e política que nosso país está vivendo é um fator relevante para a situação de instabilidade em que se encontra o mercado de trabalho, pois esta está afetando empresas de todos os ramos de atividades. Assim, com o desemprego, há menos consumo e conseqüentemente, mais pessoas desempregadas. $O$ terceiro objetivo específico visava verificar os recursos que estão sendo tomados pelo público-alvo diante dessa situação e, assim, identificou-se que as pessoas buscam alternativa de renda nas atividades sem carteira assinada e contam com a ajuda de pessoas próximas.

Quanto ao quarto objetivo específico, este visava apontar os impasses entre oferta e procura de emprego na percepção de pessoas desempregadas. No que se refere ao recrutamento e seleção, a pesquisa demonstra que os respondentes vêem a forma que as empresas conduzem o processo de seleção como outro fator a ser melhorado, possibilitando aos candidatos e a empresa melhor êxito nesta busca. Sugere-se que essa questão deva ser aprofundada em outro estudo para que seja possível analisar e compreender os fatores que envolvem o recrutamento e seleção.

Os objetivos propostos neste estudo foram atingidos, mas reconhece-se como uma limitação o fato de que a busca pelos dados ocorreu on-line, o que 
representa que apenas a população que tem acesso a tecnologias da informação e comunicação responderam a pesquisa.

Este estudo contribuiu para uma melhor compreensão do mercado de trabalho e a situação do desemprego, afinal este tema está muito presente no cotidiano da população e afeta não apenas quem está em situação de desemprego, mas a vida econômica das pessoas em geral. Além disso, este estudo poderá influenciar na reflexão das empresas sobre novas estratégias nos processos de recrutamento e seleção, a fim de dirimir dificuldades encontradas tanto por candidatos a emprego, quanto pelas próprias organizações.

\section{REFERÊNCIAS}

ALMEIDA, Walnice. Captação e seleção de talentos: com foco em competências. 2. ed. São Paulo: Atlas, 2009.

ARAÚJO, Antônio de Pádua; ALBUQUERQUE, Lindolfo Galvão de; SILVA, Leilianne Michelle Trindade da. Mercado de trabalho e gestão de pessoas: mudanças e desafios. In: ALBUQUERQUE, Lindolfo Galvão de; LEITE, Nildes Pitombo (Orgs.). Gestão de pessoas: perspectivas estratégicas. São Paulo: Atlas, 2009.

BANOV, Márcia Regina. Recrutamento, seleção e competências. 3. ed. São Paulo: Atlas, 2012.

BARBIERI, Ugo Franco. Gestão de pessoas nas organizações: o talento humano na sociedade da informação. São Paulo: Atlas, 2014.

CAREGNATO, Rita Catalina Aquino; MUTTI, Regina. Pesquisa qualitativa: Análise de discursos versus análise de conteúdo. Texto Contexto Enferm., Florianópolis, v. 15, n. 4, p. 679-84, out./dez. 2006.

CARVALHO, Iêda Maria Vecchioni; PASSOS, Antônio Eugênio Valverde Mariani; SARAIVA, Suzana Barros Corrêa. Recrutamento e seleção por competências. Rio de Janeiro: FGV, 2008.

CHIAVENATO, Idalberto. Planejamento, recrutamento e seleção de pessoal: como agregar talentos à empresa. 7. ed. rev. atual. Barueri: Manole, 2009.

Gestão de pessoas. 3. ed. Rio de Janeiro: Elsevier, 2010.

DESEMPREGO atinge 11,8 milhões de pessoas. Jornal do Comércio, 31 ago. 2016. Disponível em: <http://jcrs.uol.com.br/_conteudo/2016/08/economia/518693desemprego-atinge-11-8-milhoes-de-pessoas.html>. Acesso em: 03 out. 2016.

DESSLER, Gary. Administração de Recursos Humanos. 3. ed. São Paulo: Pearson Education do Brasil, 2014. E-book. Disponível em: <http:/ /www.univates.br/ biblioteca>. Acesso em: 05 out. 2016. 
DUTRA, Joel Souza. Administração de carreiras: uma proposta para repensar a gestão de pessoas. São Paulo: Atlas, 2011.

DUTRA-THOME, Luciana; KOLLER, Silvia Helena. O significado do trabalho na visão de jovens brasileiros: uma análise de palavras análogas e opostas ao termo "trabalho". Revista de Psicologia, Organ. Trab., Florianópolis, v. 14, n. 4, p. 367-380, dez. 2014. Disponível em: <http:/ / pepsic.bvsalud.org/scielo.php?script=sci_arttext\&pid=S198466572014000400004\&lng=pt\&nrm=iso $>$. Acesso em: 27 mai. 2016.

FACHIN, Odilia. Fundamentos de metodologia. 4. ed. São Paulo: Saraiva, 2003.

FREUND, J. E.; SIMON, G. A. Estatística aplicada. 9. ed. Porto Alegre: Bookman, 2000.

Falta trabalho para 27,7 milhões de pessoas, diz IBGE. Folha de S. Paulo, 17 mai. 2018. Disponível em: https:/ / www1.folha.uol.com.br/mercado/2018/05/falta-trabalhopara-277-milhoes-de-pessoas-diz-ibge.shtml Acesso em: 17 mai. 2018.

GIL, Antonio Carlos. Gestão de pessoas: enfoque nos papéis profissionais. São Paulo: Atlas, 2001.

. Métodos e técnicas de pesquisa social. 6. ed. São Paulo: Atlas, 2012.

IVANCEVICH, John M. Gestão de recursos humanos. 10. ed. São Paulo: McGrawHill, 2008.

JUNIOR, Adalton Honório et al. Processo de recrutamento e seleção: uma análise das dificuldades encontradas pelos colaboradores. Anais CEAD \& CIESTEC, 2014. Disponível em: <http:/ / revista.fafijan.br/index.php/ACC/article/view/21/18>. Acesso em: 04 out. 2016.

LACOMBE, Francisco. Recursos humanos: princípios e tendências. 2. ed. São Paulo: Saraiva, 2011.

LAKATOS, Eva Maria; MARCONI, Marina de Andrade. Fundamentos de metodologia científica. 7. ed. São Paulo: Atlas, 2010.

LENA, Renato César. Trabalho, emprego e empregabilidade. In: BARDUCHI, Ana Lúcia Jakovic... [et al]. Empregabilidade: competências pessoais e profissionais. São Paulo: Pearson Prentice Hall, 2010. E-book. Disponível em: <http:/ / www.univates. br/biblioteca>. Acesso em: 02 abr. 2016.

MALHOTRA, Naresh K. Pesquisa de marketing: uma orientação aplicada. 6. ed. Porto Alegre: Bookman, 2012.

MARRAS, Jean Pierre. A gestão de pessoas na era do conhecimento. In: MARRAS, Jean Pierre (Org.). Gestão estratégica de pessoas: conceitos e tendências. São Paulo: Saraiva, 2010. 
MILKOVICH, George T.; BOUDREAU, John W. Administração de recursos humanos. São Paulo: Atlas, 2013.

PNAD Contínua: taxa de desocupação é de 11,8\% no trimestre encerrado em agosto de 2016. IBGE, 30 set. 2016. Disponível em: <http:/ / saladeimprensa.ibge.gov.br/ noticias.html? view =noticia\&id=1\&idnoticia=3269\&busca=1\&t=pnad-continua-taxadesocupacao-11-8-trimestre-encerrado-agosto-2016>. Acesso em: 03 out. 2016.

PNAD Contínua: taxa de desocupação é de 13,1\% no trimestre encerrado em março. IBGE, 27 abr. 2018. Disponível em: <https:/ /agenciadenoticias.ibge.gov.br/agenciasala-de-imprensa/2013-agencia-de-noticias / releases/20994-pnad-continua-taxa-dedesocupacao-e-de-13-1-no-trimestre-encerrado-em-marco.html>. Acesso em: 16 mai. 2018 .

SAMPIERI, Roberto Hernández; COLLADO, Carlos Fernández; LUCIO, Maria del Pilar Baptista. Metodologia de pesquisa. 5. ed. Porto Alegre: Penso, 2013.

SANTOS, Geórgia P. G. D. Desemprego, informalidade e precariedade: a situação do mercado de trabalho no Brasil pós-1990. São Paulo: Pro-Posições, 2008. Disponível em: <http://www.scielo.br/pdf/pp/v19n2/a11v19n2>. Acesso em: 04 out. 2016.

SÓ 14\% DOS ADULTOS brasileiros têm Ensino Superior, diz estudo. Folha de São Paulo, 15 set. 2016. Disponível em: <http:/ / www1.folha.uol.com.br/ educacao/2016/09/1813715-so-14-dos-adultos-brasileiros-tem-ensino-superior-dizrelatorio-da-ocde.shtml>. Acesso em: 04 out. 2016.

VERGARA, Sylvia Constant. Projetos e relatórios de pesquisa em administração. 12. ed. São Paulo: Atlas, 2010.

VIZIOLI, Miguel (Cons.). Administração de recursos humanos. São Paulo: Pearson Education do Brasil, 2010. 